\title{
Modeling and PSO Optimization of Humidifier-Dehumidifier Desalination
}

\author{
Mohammad A. Afshara, Ali Naseria, Mokhtar Bidia, Mohammad H. Ahmadi b**, H. \\ Hadiyanto ${ }^{c}$ \\ ${ }^{a}$ Faculty of Mechanical and Energy Engineering, Shahid Beheshti University, A.C., Tehran, Iran \\ ${ }^{b}$ Faculty of Mechanical Engineering, Shahrood University of Technology, Shahrood, Iran \\ 'Department of Chemical Engineering, Diponegoro University, Jl. Prof. Soedarto, Tembalang, Semarang, 50239, Indonesia
}

\begin{abstract}
The aim of this study is modeling a solar-air heater humidification-dehumidification unit with applying particle swarm optimization to find out the maximum gained output ratio with respect to the mass flow rate of water and air entering humidifier, mass flow rate of cooling water entering dehumidifier, width and length of solar air heater and terminal temperature difference (TTD) of dehumidifier representing temperature difference of inlet cooling water and saturated air to dehumidifier as its decision variable. A sensitivity analysis, furthermore, is performed to distinguish the effect of operating parameters including mass flow rate and streams' temperature. The results showed that the optimum productivity decreases by decreasing the ratio of mass flow rate of water entering humidifier to air ones.
\end{abstract}

Keywords: humidification-dehumidification desalination, GOR, solar air collector, PSO

Article History: Received: July 12th 2017; Revised: December 15th 2017; Accepted: 2nd February 2018; Available online

How to Cite This Article: Afshar, M.A., Naseri, A., Bidi, M., Ahmadi, M.H. and Hadiyanto, H. (2018) Modeling and PSO Optimization of Humidifier-Dehumidifier Desalination. International Journal of Renewable Energy Development, 7(1),59-64.

https://doi.org/10.14710/ijred.7.1.59-64

\section{Introduction}

Need for available and sufficient quantity of fresh water is a fundamental requirement of human living, while, in many parts of the world suffer people from lack of fresh water. However, abundance of solar energy in those areas led to use this energy to produce fresh water with desalination technologies. Nowadays, solar water humidification-dehumidification (HD) desalinations are one of the most simple and efficient ones. Some studies have been performed to model and improve the efficiency of these systems. Mistry optimized HD desalination using nonlinear programming techniques which results in maximum gained output ratio (GOR) (Mistry et al. 2011). Mehrgoo modeled a multi-effect HD desalination unit and produces a shape and structure optimization procedure (Mehrgoo et al. 2011a). A genetic algorithm (GA) is used to maximize GOR. The same author also applied the concept of constructal design proposed by Bejan examined the geometric aspects of these systems (Mehrgoo et al. 2011b). Furthermore, he optimized a direct contact HD unit using GA method and Lagrangian multipliers method to increase production rate (Mehrgoo et al. 2012). Khalid M. Abd El-Aziz modelled and optimized a water-heated HD unit by disconnecting the condenser from the saline water and used a solar air heater to have further performance (El-Aziz et al. 2014). R. Gonzalez, moreover, proposed a design algorithm for multi-effect HD desalinations (Gonzalez et al. 2009). J. Orfi theoretically and experimentally studied solar water driven HD desalination system (Orfi et al. 2004), and Chafik used a stepwise heating and humidifying technique to present a new solar-water desalination process (Chafik 2002).

In this model, a sensitivity analysis is applied on operating parameters such as mass flow rate of air and water and their temperature and a particle swarm optimization is used to maximize gained output ratio related to mass flow rate of water and air entering humidifier, width and length of solar air heater, mass flow rate of cooling water entering dehumidifier and terminal temperature difference (TTD) of dehumidifier which represented temperature difference between cooling water enters dehumidifier and saturated air.

\footnotetext{
* Corresponding author email: mohammadhosein.ahmadi@gmail.com
} 
Citation: Afshar, M.A., Naseri, A., Bidi, M., Ahmadi, M.H. and Hadiyanto, H. (2018) Modeling and PSO Optimization of Humidifier-Dehumidifier Desalination.Int. Journal of Renewable Energy Development, 7(1),59-64, doi.org/10.14710/ijred.7.1.59-64

$\mathrm{P}$ a g e $\mid 60$

\section{Materials and Methods}

\subsection{System description and modeling}

The schematic of the proposed solar-air collector HD desalination is shown in Figure 1. The system includes three sub-systems, namely one-pass solar-air heater, humidification column and dehumidification column. The forced air enters the heater, at first, and then absorbs radiation of sun, increasing its temperature. As the air and not heated water enter humidification column, simultaneously, it humidified by saline water. The air carrying water vapor enters dehumidification column and passes through its cold water coils and results in fresh water, finally. In order to model the system, the following assumptions are considered to simplify the model:

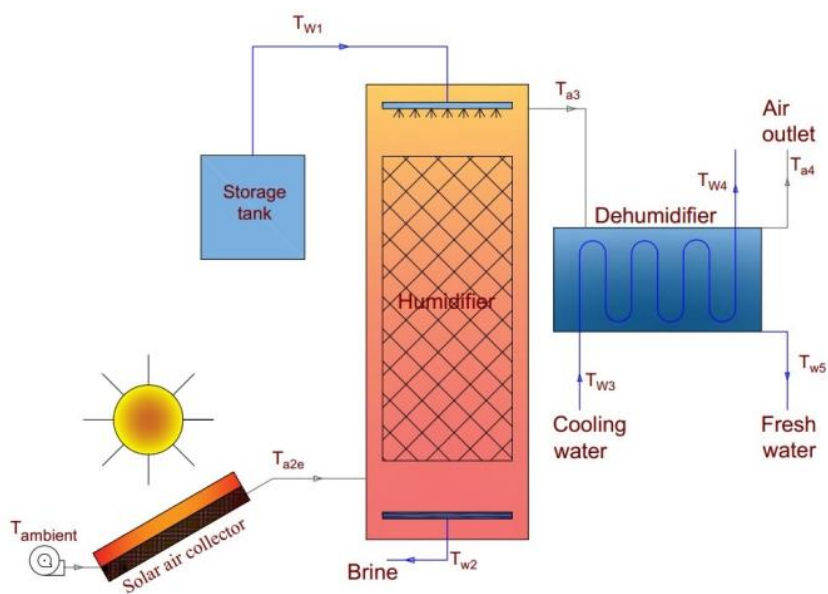

Fig. 1 The proposed model schematic

- Heat loss to the ambient from the edges of the solar-air heated, humidifier and dehumidifier columns are neglected.

- There is no air leakage from heater during the process of heating.

- The temperature of the outlet water entering dehumidification column is equal to wet-bulb temperature of humidifier leaving air.

- The Bypass Factor for humidification column is equal to one, so the leaving air from the humidifier is saturated.

- The process of dehumidification lies on the saturation curve.

- The temperature of fresh water leaving dehumidifier, the dry-bulb temperature of air leaving dehumidifier and ejecting cooling water temperature are equal.

- The dehumidification heat exchanger is parallel flow.

- Solar radiation, relative humidity of ambient and its temperature is constant during the process.

- Both laminar and turbulent flow in the process is fully-developed.

\subsection{Equations}

Using the assumptions, and applying energy balance for each sub-system, the equations are as follow:

a. Humidifier and Dehumidifier (Yamalı et al. 2007)

$$
\begin{aligned}
& M_{a i r}\left(h_{a 3}-h_{a 2_{-} e}\right)=M_{w 1} C p_{w} T_{w 1}-M_{w 2} C p_{w} T_{w 2} \\
& M_{w 2}=M_{w 1}-M_{a i r}\left(\omega_{a 3}-\omega_{a 2 \_}\right) \\
& M_{a i r}\left(h_{a 3}-h_{a 4}\right)=M_{w 3} C p_{w}\left(T_{w 4}-T_{w 3}\right)+M_{c} C p_{w} T_{w 5} \\
& M_{w 2}=M_{w 1}-M_{a i r}\left(\omega_{a 3}-\omega_{a 2 \_}\right)
\end{aligned}
$$

b. Solar-air heater (Kalogirou 2013; Naseri et al. 2017a,b):

$M_{\text {air }}\left(h_{a 3}-h_{a 4}\right)=M_{w 3} C p_{w}\left(T_{w 4}-T_{w 3}\right)+M_{c} C p_{w} T_{w 5}$

Where $\mathrm{A}_{c}, \mathrm{~F}_{\mathrm{R}}$ and $S$ are total absorber area, heat removal factor and total absorbed solar radiation. In this equation $F_{R}$ is calculated as below:

$$
\begin{aligned}
& F_{R}=\frac{M C p}{A_{C} U_{\text {total }}}\left[1-\exp \left(\frac{A_{c} U_{\text {total }} F^{\prime}}{M C p}\right)\right] \\
& F^{\prime}=h / h+U_{\text {total }}
\end{aligned}
$$

Where $h$ stands for air heat transfer coefficient. Moreover, in order to calculate air properties, the following equations are used in which $T$ is dry bulb temperature of the air (Al-Sahali et al. 2008):

$$
\begin{aligned}
& C p_{\text {air }}=1.0340-2.8488 \times 10^{-4} T+7.81681 \times 10^{-7} T^{2} \\
& -4.97078 \times 10^{-10} T^{3}+1.07702 \times 10^{-13} T^{4} \\
& K_{\text {air }}=1 \times 10^{-3}\left(-2.276501 \times 10^{-3}+1.2598485 \times 10^{-4} T\right. \\
& -1.4815235 \times 10^{-7} T^{2}+1.73550646 \times 10^{-10} T^{3}- \\
& \left.1.066657 \times 10^{-13} T^{4}+2.47663035 \times 10^{-17} T^{5}\right) \\
& \mu_{\text {air }}=1 \times 10^{-6}\left(-0.98601+9.080125 \times 10^{-2} T-1.17635575 \times 10^{-4} T^{2}\right. \\
& +1.2349703 \times 10^{-7} T^{3}-5.7971299 \times 10^{-11} T^{4}
\end{aligned}
$$

Fan consumption (Yamalı et al. 2007):

$$
\begin{gathered}
W_{\text {fan }}=M_{\text {air }} \Delta P_{\text {fan }} / \rho_{\text {air }} \eta_{\text {fan }} \\
\Delta P_{\text {fan }}=\rho g\left[f \frac{L}{D} \frac{V^{2}}{2 g}\right]
\end{gathered}
$$

Where $f$ stands for the air friction factor.

\section{Particle Swarm Optimization}

This method is based on swarm encompassing combination of volume less particles with velocities representing the direction for particles' movement. 
These particles are feasible solutions in solution space and objective function value is calculated by particles in their situations. This uses a combination of current location information, last best location of particle and the information of one or more best particles in the swarm to select the directions for moving. This repeating process continues up to find the optimal solution measured by moving particles in solution space. This practical process could be formulized as follow. It is supposed that there is an m-dimensional search area. So, $X_{i}=\left[X_{i 1}, X_{i 2}, X_{i 3}, \ldots, X_{i m}\right]^{T}$ and $V_{i}=\left[V_{i 1}, V_{i 2}, V_{i 3}, \ldots, V_{i m}\right]^{T}$ present the current position and velocity of $i$ th particle, respectively, in which $N$ shows the number of particles. Furthermore,
$L_{i}=\left[L_{i 1}, L_{i 2}, L_{i 3}, \ldots, L_{i m}\right]^{T}$ is the best position of $i$ th particle that it ever visited and is known as the local best position, while the best position of whole swarm or global best position is shown by $G=\left[G_{1}, G_{2}, G_{3}, \ldots, G_{m}\right]^{T}$. The position and velocity of $i$ th particle is randomly considered and the position and velocity of $i$ th particle in iteration $t+1$ is adjusted to the local and global best positions of iteration $t$, consequently. So:

$$
\begin{aligned}
& V_{i}^{(t+1)}=\omega V_{i}^{(t)}+c_{1} R_{1}\left(L_{i}^{(t)}-X_{i}^{(t)}\right)+c_{2} R_{2}\left(G^{(t)}-X_{i}^{(t)}\right) \\
& X_{i}^{(t+1)}=X_{i}^{(t)}+V_{i}^{(t+1)}
\end{aligned}
$$

Table 1

Previous works on HD desalination optimization

\begin{tabular}{lcc}
\hline \multicolumn{1}{c}{ Sources } & Obj. function & Method \\
\hline Mistry et al. 2011 & GOR & NLP \\
Mehrgoo et al. $2011 \mathrm{a}$ & GOR & GA \\
Mehrgoo et al. $2011 \mathrm{~b}$ & Constructal design & GA \\
Mehrgoo et al. 2012 & Production rate & GA and Lagrangian multipliers \\
El-Aziz et al. 2014 & Cost & Tailored optimization \\
Soufari et al. 2009 & Performance & NLP \\
Zamen et al. 2009 & Cost & NLP \\
This work & GOR & PSO
\end{tabular}

In these equations, $\omega$ stands for the inertia coefficient controlling previous history of velocities on the current velocities effect, $C 1$ and $C 2$ are the local and global best positions accelerate coefficients representing the attraction of particle toward its own or neighbors' success, and $R 1$ and $R 2$ are random real numbers between 0 through 1 , subsequently. Updating the velocity, the position of $i$ th particle in the iteration $t+1$ is calculated by equation (13) and this continues up until the iterations' number has been exceeded (Sun et al. 2012).

In Table 1, a summary of previous work in desalination optimization is presented by their objective functions and optimization methods were used. So, based on the table there is no work in humidification dehumidification desalinations optimization in the field of particle swarm optimization.

\section{Results and discussion}

Numerical simulation of solar-air heater HD desalination is performed by development of mathematical model based on mentioned equation and a summarized simulation condition of the system is given by Table 2. Moreover, Figure 2 compares the variation of distilled water flow rate with respect to inlet water and air flow rate to humidifier, respectively, while the other parameters are constant.
Table 2

Simulation Condition of model

\begin{tabular}{cccc}
\hline Parameter & Value & Parameter & Value \\
\hline$W$ & $0.5(\mathrm{~m})$ & $M_{w 3}$ & $0.05(\mathrm{~kg} / \mathrm{s})$ \\
$L$ & $1.0(\mathrm{~m})$ & $M_{w 1}$ & $0.028(\mathrm{~kg} / \mathrm{s})$ \\
$S$ & $700\left(\mathrm{~W} / \mathrm{m}^{2}\right)$ & $M_{A i r}$ & $0.005(\mathrm{~kg} / \mathrm{s})$ \\
$P_{\text {air }}$ & $101(\mathrm{kPa})$ & $T_{w 3}$ & $15\left({ }^{\circ} \mathrm{C}\right)$ \\
$\omega_{\text {air }}$ & $0.5(\mathrm{~kg} / \mathrm{kg})$ & $T_{w 1}$ & $25\left({ }^{\circ} \mathrm{C}\right)$ \\
$T T D_{D H}$ & 2.0 & $T_{A i r}$ & $25\left({ }^{\circ} \mathrm{C}\right)$ \\
\hline
\end{tabular}

It is obvious that, increasing inlet water mass flow rate to humidifier raises the amount of distilled water, while the air mass flow rate reaches a peak in fresh water production as it goes on. In a specified inlet water mass flow rate to humidifier, the more air mass flow rate, the less wet-bulb temperature at the outlet of solar air collector and consequently as dry-bulb temperature of air leaving the humidifier decreases up to get closer to wet-bulb temperature of air entering humidifier, the air ability to get more moisture falls and the rate of humidification decreases.

However, in order to perform PSO method, Gained Output Ratio (GOR) is considered as an objective function which calculated by using Eq 15 . 
Citation: Afshar, M.A., Naseri, A., Bidi, M., Ahmadi, M.H. and Hadiyanto, H. (2018) Modeling and PSO Optimization of Humidifier-Dehumidifier Desalination.Int. Journal of Renewable Energy Development, 7(1),59-64, doi.org/10.14710/ijred.7.1.59-64

$\mathrm{P}$ a g e $\mid 62$

$$
G O R=M_{c} h_{f g} /\left(Q_{\text {heater }}+W_{f a n}\right)[k j / k j]
$$

Also, to evaluate the effect of each operating parameters on objective function value, a sensitivity analysis is applied to each variable based on equation (16), and the results are represented in Figure 3. As it can be seen by the figure, the value of GOR is strongly depends on changes in inlet water to humidifier temperature and the cooling water entering dehumidifier column temperature. So, any little changes in these two parameters results in noticeable change in GOR value.

$S_{\text {Var }}^{O b j}=\frac{d(O b j)}{d(\operatorname{Var})} / \frac{O b j}{V a r}$

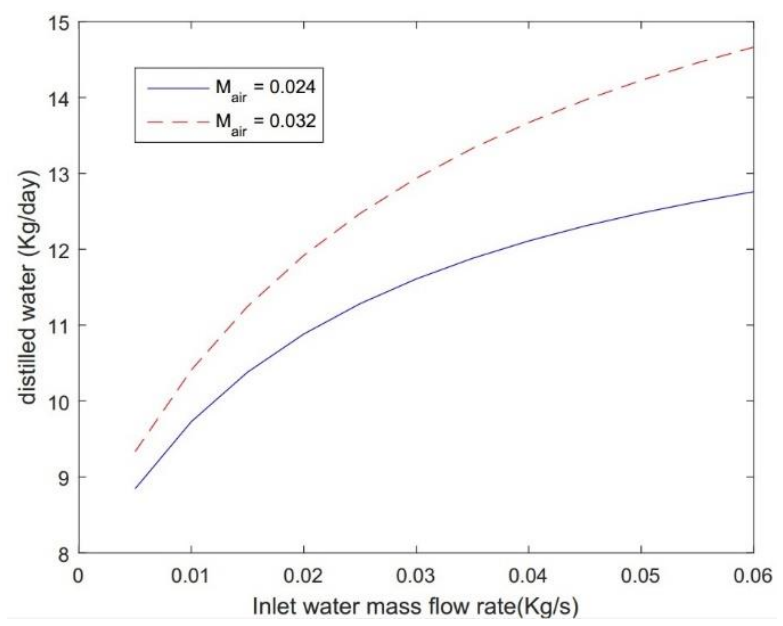

Fig. 2a Distilled water changes to inlet water flow rate

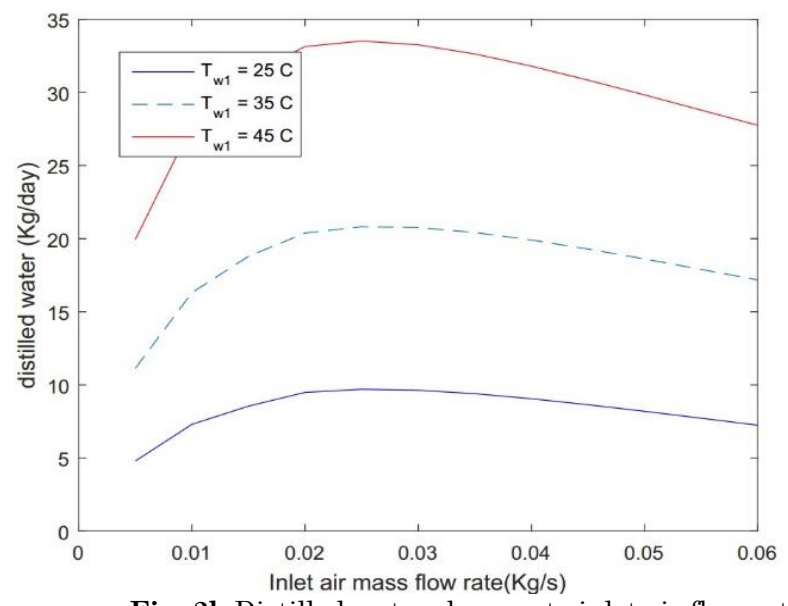

Fig. 2b Distilled water changes to inlet air flow rate

As it can be seen in Figure 3, the objective function extremely varies by any change in the temperature of inlet water to humidifier and cooling water entering dehumidifier, while mass flow rates variation effects are considerably less than it. The absorber late width and length also are in the second place. Indeed, increasing the temperature of cooling water leads to noticeably reduction in fresh water mass flow rate due to fall in temperature difference between coolant and humid air. Thus, the below boundaries were considered to determine the optimum value of objective function (Al-Sahali et al. 2008):

$$
\begin{aligned}
& 0.005 \leq M_{w 1} \leq 0.06 \\
& 0.005 \leq M_{A i r} \leq 0.06 \\
& 0.005 \leq M_{w 3} \leq 0.08 \\
& 0.5 \leq L \leq 2 \\
& 0.5 \leq W \leq 2 \\
& 2 \leq T T D_{D H} \leq 6
\end{aligned}
$$

As the result, the optimized values for mentioned boundaries and also the maximum gained output ratio are shown in Table 3.

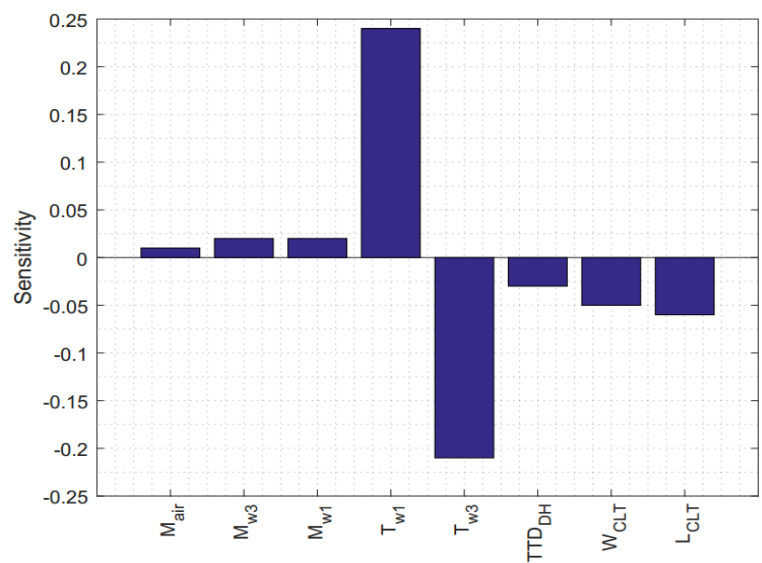

Fig. 3 Sensitivity analysis of humidification and dehumidification parameters

Table 3

Optimized value for the HD desalination

\begin{tabular}{cccc} 
Parameter & Value & Parameter & Value \\
\hline$W$ & $0.5(\mathrm{~m})$ & $M_{w 3}$ & $0.0056(\mathrm{~kg} / \mathrm{s})$ \\
$L$ & $0.5(\mathrm{~m})$ & $M_{w 1}$ & $0.0058(\mathrm{~kg} / \mathrm{s})$ \\
$T T D_{D H}$ & 6.0 & $M_{A i r}$ & $0.0064(\mathrm{~kg} / \mathrm{s})$ \\
$G O R$ & $0.53(\mathrm{~kJ} / \mathrm{kJ})$ & & \\
\hline
\end{tabular}

Any changes in input parameters will alter the optimal solution and it shown that changing unit operating conditions affect the production rate. Thus, if the ratio of mass flow rate of water entering humidifier to air ones change, maximum productivity of unit change in the same direction. This is evident in Figure 4, as the ratio of inlet water to inlet air to humidifier increases $(\mathrm{L} / \mathrm{G})$, the optimum production rate also rises. 


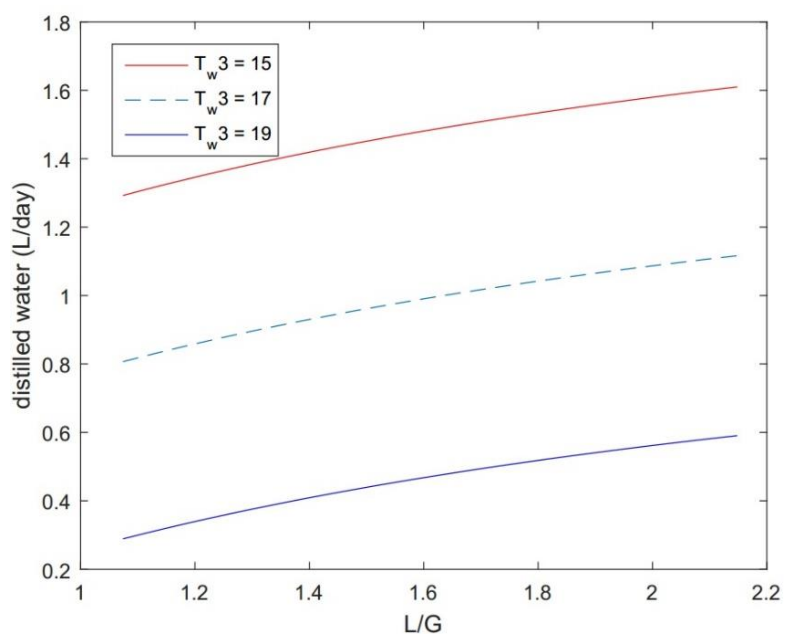

Fig. 4 Optimum production changes due to changes in the ratio of input water to input air

\section{Conclusion}

A numerical study was performed to study the effect of some parameters on fresh water production rate on solar-air heater humidification-dehumidification desalination. Furthermore, a sensitivity analysis is applied to investigate the effect of some parameters on gained output ratio and a particle swarm optimization is utilized to measure the optimum value of objective function related to considered boundaries for decision parameters. It is shown that humidifier column's inlet water temperature and cooling water in dehumidification have the most effects on production rate. Any changes in ratio of inlet water to inlet air to humidifier, moreover, changes optimum distilled water value.

\section{Nomenclatures}

$\begin{array}{ll}A_{c} & \text { Collector area }\left(\mathrm{m}^{2}\right) \\ C p & \text { Heat Capacity }(\mathrm{j} / \mathrm{kg} . \mathrm{K}) \\ C L T & \text { Solar air collector } \\ D H & \text { Dehumidifier } \\ P & \text { Pressure }(\mathrm{Pa}) \\ \eta & \text { Efficiency }(\%) \\ f & \text { Friction factor } \\ F_{R} & \text { Heat removal factor } \\ g & \text { Gravity }\left(\mathrm{m}^{2} / \mathrm{s}\right) \\ h & \text { Enthalpy }(\mathrm{kj} / \mathrm{kg}) ; \text { heat transfer coefficient }\left(\mathrm{W} / \mathrm{m}^{2} . \mathrm{K}\right) \\ K & \text { Thermal conductivity (W/m.K) } \\ L & \text { Length of collector }(\mathrm{m}) \\ M & \text { Mass flow rate }(\mathrm{kg} / \mathrm{s}) \\ M_{c} & \text { Mass flow rate of distilled water }(\mathrm{kg} / \mathrm{s}) \\ Q_{u} & \text { Useful heat gain by solar-air heater }(\mathrm{kW}) \\ \rho & \left.\text { Density (kg/m }{ }^{3}\right), \\ S & \text { Total incident flux absorbed }\left(\mathrm{W} / \mathrm{m}^{2}\right)\end{array}$

$\begin{array}{ll}T & \text { Temperature }\left({ }^{\circ} \mathrm{C}\right) \\ U & \text { Overall heat loss coefficient }\left(\mathrm{W} / \mathrm{m}^{2} \cdot \mathrm{K}\right) \\ V & \text { Velocity }(\mathrm{m} / \mathrm{s}) \\ W & \text { Work }(\mathrm{kW}), \text { Width of collector }(\mathrm{m}) \\ \omega & \text { Relative humidity }(\mathrm{kg} / \mathrm{kg})\end{array}$

\section{References}

Al-Sahali, M., \& Ettouney, H. M. (2008). Humidification dehumidification desalination process: Design and performance evaluation. Chemical Engineering Journal, $143(1), 257-264$.

Chafik, E. (2003). A new seawater desalination process using solar energy. Desalination, 153(1-3), 25-37.

El-Aziz, K. M. A., Hamza, K., El Morsi, M., Nassef, A. O., Metwalli, S. M., \& Saitou, K. (2014, August). Optimum Solar HDH Desalination for Semi-Isolated Communities Using HGP and GA's. In ASME 2014 International Design Engineering Technical Conferences and Computers and Information in Engineering Conference (pp. V02AT03A020V02AT03A020). American Society of Mechanical Engineers.

González, R., Pieretti, P., \& Díaz, H. (2009, January). Design Algorithm of a Multi-Effect Humidification-Dehumidification Solar Distillation System. In ASME 2009 International Mechanical Engineering Congress and Exposition (pp. 111115). American Society of Mechanical Engineers.

Kalogirou, S. A. (2013). Solar energy engineering: processes and systems. Academic Press.

Mehrgoo, M., \& Amidpour, M. (2011). Constructal design of humidification-dehumidification desalination unit architecture. Desalination, 271(1), 62-71.

Mehrgoo, M., \& Amidpour, M. (2011). Derivation of optimal geometry of a multi-effect humidification-dehumidification desalination unit: A constructal design. Desalination, 281, 234-242.

Mehrgoo, M., \& Amidpour, M. (2012). Constructal design and optimization of a direct contact humidificationdehumidification desalination unit. Desalination, 293, 69-77.

Mistry, K. H., Mitsos, A., \& Lienhard, J. H. (2011). Optimal operating conditions and configurations for humidificationdehumidification desalination cycles. International Journal of Thermal Sciences, 50(5), 779-789.

Naseri, A., Bidi, M., \& Ahmadi, M. H. (2017). Thermodynamic and exergy analysis of a hydrogen and permeate water production process by a solar-driven transcritical CO 2 power cycle with liquefied natural gas heat sink. Renewable Energy.

Naseri, A., Bidi, M., Ahmadi, M. H., \& Saidur, R. (2017). Exergy analysis of a hydrogen and water production process by a solar-driven transcritical CO 2 power cycle with Stirling engine. Journal of Cleaner Production, 158, 165-181.

Soufari, S. M., Zamen, M., \& Amidpour, M. (2009). Performance optimization of the humidification-dehumidification desalination process using mathematical programming. Desalination, 237(1-3), 305-317.

Sun, Z., Wang, J., Dai, Y., \& Wang, J. (2012). Exergy analysis and optimization of a hydrogen production process by a solarliquefied natural gas hybrid driven transcritical $\mathrm{CO} 2$ power cycle. international journal of hydrogen energy, 37(24), 18731-18739.

Yamalı, C., \& Solmuş, İ. (2007). Theoretical investigation of a humidification-dehumidification desalination system configured by a double-pass flat plate solar air heater. Desalination, 205(1-3), 163-177.

Younis, M. A., Darwish, M. A., \& Juwayhel, F. (1993). Experimental and theoretical study of a humidification- 
Citation: Afshar, M.A., Naseri, A., Bidi, M., Ahmadi, M.H. and Hadiyanto, H. (2018) Modeling and PSO Optimization of Humidifier-Dehumidifier Desalination.Int. Journal of Renewable Energy Development, 7(1),59-64, doi.org/10.14710/ijred.7.1.59-64

$\mathrm{P}$ a g e $\mid 64$

dehumidification desalting system. Desalination, 94(1), 1124.

Zamen, M., Amidpour, M., \& Soufari, S. M. (2009). Cost optimization of a solar humidification-dehumidification desalination unit using mathematical programming. Desalination, 239(1-3), 92-99. 